\title{
Penguasaan Konsep Fluida Statis Siswa SMA
}

\author{
Zaitul Harizah ${ }^{1}$, Sentot Kusairi ${ }^{1}$, Eny Latifah ${ }^{1}$ \\ ${ }^{1}$ Pendidikan Fisika-Universitas Universitas Negeri Malang
}

\begin{tabular}{l} 
INFO ARTIKEL \\
\hline Riwayat Artikel: \\
Diterima: $10-05-2019$ \\
Disetujui: $10-12-2019$ \\
\hline
\end{tabular}

\section{Kata kunci:}

mastery of concept; static fluid; penguasaan konsep; fluida statis

\begin{abstract}
ABSTRAK
Abstract: This study aims to analyze the mastery of students' concepts in static fluid material. The subjects in this study were students of class XII IPA 1 MAN 1 Pamekasan which consist of 40 students. The study was conducted using a survey method and used a multiple choice test with open reasons consisting of 9 items. The results showed the mastery of students' concepts was low. The average acquisition score of students' concept mastery was 33,06. The most students' difficult are found in Archimedes' Law. Students haven't mastered the concept of buoyancy so well, so students' couldn't answers correctly the questions.
\end{abstract}

\begin{abstract}
Abstrak: Penelitian ini bertujuan untuk menganalisis penguasaan konsep siswa pada materi fluida statis. Subjek dalam penelitian ini yaitu siswa kelas XII IPA 1 MAN 1 Pamekasan yang berjumlah 40 siswa. Penelitian dilakukan dengan menggunakan metode survei dan memberikan instrumen tes berbentuk pilihan ganda dengan alasan terbuka yang terdiri dari sembilan butir soal. Hasil penelitian menunjukkan bahwa penguasaan konsep siswa masih rendah. Rata-rata perolehan skor penguasaan konsep siswa sebesar 33,06. Kesulitan siswa paling banyak ditemukan pada bahasan Hukum Archimedes. Siswa belum menguasai konsep gaya apung dengan baik sehingga tidak ada siswa yang menjawab dengan benar soal yang berkaitan dengan gaya apung ini.
\end{abstract}

\author{
Alamat Korespondensi: \\ Zaitul Harizah \\ Pendidikan Fisika \\ Universitas Negeri Malang \\ Jalan Semarang 5 Malang \\ E-mail: zaitulharizah@ gmail.com
}

Fisika diberikan kepada siswa untuk melatih siswa memiliki pemikiran dan bertindak seperti ilmuan. Dengan melatihkan kemampuan berpikir seperti para ilmuan agar siswa dapat menguasai konsep secara menyeluruh (Fakcharoenphol dkk, 2015). Sejauh ini terdapat beberapa kendala dalam melatihkan siswa untuk berpikir seperti ilmuan. Siswa sering mengalami kesulitan menguasai konsep fisika karena siswa telah memiliki konsepsi yang berbeda dengan apa yang sedang siswa pelajari (Miller dkk, 2013). Siswa juga merasa tidak tertarik belajar fisika karena menurut siswa, fisika terdiri dari materi yang sulit dipahami (Ozcan, 2015).

Fluida statis merupakan salah satu materi dalam fisika yang aplikasinya dekat dengan kehidupan sehari-hari siswa. Meskipun begitu, siswa terkadang masih sulit dalam menguasai konsep dari fluida statis. Beberapa kesulitan yang dialami siswa pada materi fluida statis yaitu pada sub bahasan Tekanan Hidrostatis, siswa menganggap volume air memengaruhi tekanan (Loverude dkk, 2010). Selain itu, siswa juga menganggap jarak dinding memengaruhi tekanan dan tekanan di semua titik dianggap sama (Goszewski dkk, 2013). Berdasarkan penelitian yang dilakukan oleh Wijaya, dkk (2016) juga menemukan bahwa siswa percaya bahwa tekanan hidrostatis bergantung pada sempit atau lebarnya suatu ruang. Pada sub bahasan Hukum Archimedes, beberapa penelitian sebelumnya menemukan bahwa siswa mengalami miskonsepsi dalam memahami Hukum Archimedes (Loverude dkk, 2003; Unal dan Costu, 2005; Yin dkk, 2008; Wong dkk, 2010). Selain itu, Yolanda (2017) menemukan bahwa siswa berpendapat bahwa faktor penyebab benda tenggelam atau terapung hanya terletak pada massa/berat benda. Memiliki penguasaan konsep yang baik sangat penting untuk siswa miliki. Rendah tingginya penguasaan konsep yang dimiliki siswa akan berpengaruh terhadap kemampuan siswa dalam menjawab soal dan dalam kehidupan sehari-hari siswa (Ipek dkk, 2010). Doctor \& Mestre (2014) juga berpendapat bahwa penguasaan konsep dibutuhkan siswa untuk menyelesaikan masalah-masalah dalam fisika. Dalam perkembangan dunia pendidikan, penguasaan konsep juga menjadi salah satu kompetensi penting yang perlu diteliti agar dapat mengevaluasi pembelajaran yang telah dilakukan (Chang dkk, 2010).

Untuk membuat siswa mencapai hasil belajar maksimalnya, terutama pada materi fluida statis, diperlukan analisis tentang penguasaan konsep siswa tentang materi tersebut untuk mengetahui sejauh mana penguasaan konsep siswa. Dengan mengetahui penguasaan konsep siswa secara mendalam, nantinya guru dapat merancang pembelajaran yang sesuai dengan kebutuhan siswa agar siswa dapat meningkatkan penguasaan konsepnya pada materi fluida statis. Ketika siswa dapat meningkatkan penguasaan konsepnya, tentunya hasil belajar yang lebih baik dapat terwujud. 


\section{METODE}

Metode yang digunakan dalam penelitian ini adalah survei. Subjek penelitian terdiri dari 40 siswa kelas XII IPA 1 di MAN 1 Pamekasan. Siswa yang digunakan dalam penelitian ini sudah mempelajari materi fluida statis ketika kelas XI. Teknik pengumpulan data melalui tes. Instrumen tes yang digunakan berupa soal pilihan ganda beralasan pada materi fluida statis. Jumlah soal tes sebanyak sembilan butir soal. Soal tes penguasaan konsep diberikan kepada siswa untuk mengetahui penguasaan konsep siswa dalam memahami materi fluida statis. Instrumen tes yang digunakan diambil dari beberapa artikel penelitian sebelumnya yang berkaitan dengan penguasaan konsep fluida statis siswa. Untuk teknik penskoran, apabila siswa memilih pilihan yang benar pada pilihan ganda siswa mendapat skor 1 dan apabila penjelasan yang diberikan siswa benar siswa mendapatkan nilai 1. Penjelasan siswa dianggap benar jika memenuhi $60 \%$ dari kunci jawaban. Jadi, skor maksimal yang siswa dapatkan untuk masing-masing soal yaitu 2. Data jawaban siswa dianalisis dengan teknik analisis deskriptif kuantitatif. Berikut distribusi soal penguasaan konsep yang digunakan pada tabel 1.

Tabel 1. Distribusi Soal Penguasaan Konsep Materi Fluida Statis

\begin{tabular}{lc}
\hline \multicolumn{1}{c}{ Bahasan } & Nomor Soal \\
\hline Tekanan Hidrostatis & $1,2,4,5$ \\
Tekanan hidrostatis bejana berhubungan & 3 \\
Hukum Pascal & 6 \\
Hukum Archimedes & $7,8,9$ \\
\hline
\end{tabular}

\section{HASIL}

Setelah data diperoleh, data dianalisis untuk mengetahui sejauh mana penguasaan konsep fluida statis siswa. Berikut ringkasan deskriptif statistik perolehan skor siswa pada materi fluida statis (Tabel 2).

Tabel 2. Ringkasan Deskriptif Statistik Perolehan Skor Penguasaan Konsep Siswa

\begin{tabular}{ll}
\hline \multicolumn{1}{c}{ Kategori } & Nilai \\
\hline Rata-rata & 33,06 \\
Maksimal & 77,78 \\
Minimal & 11,11 \\
Standar Deviasi & 19,80 \\
Median & 25,00 \\
Modus & 22,22 \\
\hline
\end{tabular}

Hasil rata-rata perolehan skor siswa sebesar 33,06 dari rentang 0-100 dengan standar deviasi 19,80. Hal ini menggambarkan bahwa penguasaan konsep fluida statis siswa masih tergolong rendah. Selain itu, tidak ada siswa yang mendapatkan skor sempurna. Skor minimum yang diperoleh siswa yaitu 11,11 dari rentang 0 - 100 dan skor maksimal yang diperoleh siswa setelah menjawab soal yaitu 77,78. dari rentang $0-100$. Untuk mengetahui persebaran skor yang diperoleh siswa pada masing-masing soal ditunjukkan pada tabel 3.

\section{Tabel 3. Ringkasan Deskriptif Statistik Perolehan Skor Penguasaan Konsep Siswa}

\begin{tabular}{clc}
\hline Nomor Soal & \multicolumn{1}{c}{ Bahasan } & Rata-Rata Perolehan Skor \\
\hline 1 & Tekanan Hidrostatis & 1,3 \\
2 & Tekanan Hidrostatis & 1,52 \\
3 & Tekanan Hidrostatis Bejana Berhubungan & 0,75 \\
4 & Tekanan Hidrostatis & 1,17 \\
5 & Tekanan Hidrostatis & 0,17 \\
6 & Hukum Pascal & 0,67 \\
7 & Hukum Archimedes & 0,3 \\
8 & Hukum Archimedes & 0 \\
9 & Hukum Archimedes & 0,05 \\
\hline
\end{tabular}

Berdasarkan tabel 3, siswa mengalami kesulitan dalam menjawab soal nomor 5, 8, dan 9. Hal ini dapat dilihat bahwa hanya rata-rata yang diperoleh butir soal nomor 5 hanya sebesar 0,17 dari rentang 0 -2, sedangkan butir soal no 8 dan 9 masing-masing memperoleh rata-rata 0 dan 0,05 dari rentang $0-2$. Hal ini menandakan bahwa hanya sedikit siswa yang berhasil menjawab ketiga soal tersebut dengan benar. Untuk rata-rata perolehan skor paling tinggi terdapat pada butir soal nomor 2 dengan rata-rata sebesar 1,52 dari rentang $0-2$. Berikut ini beberapa soal penguasaan konsep yang memiliki rata-rata perolehan skor tertinggi dan terendah. 


\section{Butir Soal Nomor 2}

Gambar di samping menunjukkan 3 wadah yang berisi air dan memiliki ketinggian air yang sama. Tekanan yang diberikan oleh air pada bagian bawah wadah adalah...

a. Sama untuk ketiga wadah (72,5\% untuk skor $2,27,5 \%$ untuk skor 1$)$ )

b. Lebih kuat di wadah A dibandingkan wadah yang lain $(0 \%)$

c. Lebih kuat di wadah B dibandingkan wadah yang lain $(0 \%)$

d. Lebih kuat di wadah $\mathrm{C}$ dibandingkan wadah yang lain $(0 \%)$

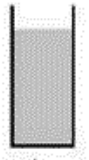

A
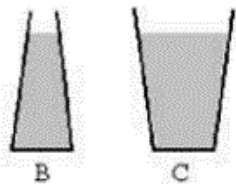

Alasan:

Pada butir soal nomor 2 sebanyak 72,5\% dari total 40 siswa menjawab dengan benar yaitu pilihan a dengan memberikan penjelasan yang benar. Sementara itu, sebanyak $27,5 \%$ siswa memilih pilihan jawaban yang benar, hanya saja siswa tersebut belum bisa memberikan penjelasan yang tepat (tidak mengisi alasan) terkait jawaban yang dipilihnya sehingga tidak bisa mendapatkan skor maksimal. Ketiga Lebih dari separuh dari jumlah siswa memilih jawaban yang benar, hal ini menandakan sebagian besar siswa memahami konsep dasar dari tekanan hidrostatis.

\section{Butir Soal Nomor 8}

Tiga buah balok dengan massa berbeda diletakkan pada wadah berisi air. Meskipun memiliki massa berbeda, bentuk dan ukuran ketiga balok tersebut sama (lihat gambar). Bagaimanakah volume air yang berubah/berpindah dengan adanya balok-balok tersebut?

a. Balok A memindahkan volume air paling banyak dan balok $\mathrm{C}$ memindahkan volume air paling sedikit ()

b. Balok $\mathrm{C}$ memindahkan volume air paling banyak dan balok $\mathrm{A}$ memindahkan volume air paling sedikit $(80,6 \%)$

c. Volume air yang dipindahkan oleh balok B dan C sama besar dan balok A memindahkan volume air paling sedikit (0\%)

d. Volume air yang dipindahkan oleh balok A paling banyak dan volume air paling yang dipindahkan olek balok C dan B sama besar $(19,4 \%)$

e. Volume air yang dipindahkan oleh ketiga balok sama banyaknya (0\%)

Alasan:

Pada butir soal nomor 8 tidak ada siswa yang menjawab dengan benar. Hal ini menandakan bahwa siswa belum sepenuhnya mengenai konsep Hukum Archimedes tentang volume zat cair yang dipindahkan oleh benda. Banyak siswa memilih pilihan jawaban b yaitu balok $\mathrm{C}$ memindahkan volume air paling banyak dan balok A memindahkan volume air paling sedikit. Siswa tidak fokus pada volume yang dipindahkan oleh balok B. Jika siswa juga memperhatikan volume yang dipindahkan oleh balok B maka siswa bisa memilih pilihan jawaban yang benar, yaitu c.

\section{Butir Soal Nomor 9}

Tiga buah balok A, B, dan C awalnya mengapung dalam bejana berisi air. Ketiga balok mempunyai volume yang sama dengan massa balok A sama dengan massa balok B, sedangkan balok C memiliki massa yang paling besar diantara ketiga balok. Balok $\mathrm{B}$ dan balok $\mathrm{C}$ kemudian diikat pada dasar wadah seperti yang ditunjukkan gambar di samping. Pernyataan yang benar di bawah ini terkait dengan gaya apung pada ketiga balok adalah ....

a. Gaya apung balok A sama dengan gaya apung balok B (0\%)

b. Gaya apung balok B sama dengan gaya apung balok C (0\%)

c. Gaya apung pada ketika balok sama besar $(6,45 \%)$

d. Balok A memiliki gaya apung paling besar $(93.55 \%)$

e. Balok $\mathrm{C}$ memiliki gaya apung paling besar $(0 \%)$

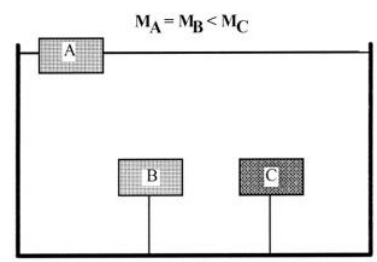

Alasan:

Pada butir soal nomor 9 tidak banyak siswa yang menjawab dengan benar. Hanya 6,45\% dari total 40 siswa yang memilih pilihan jawaban yang benar yaitu c, tetapi siswa tersebut tidak memberikan alasan (jawaban kosong) sehingga tidak mendapatan skor maksimal. Sebagian besar siswa memilih pilihan jawaban d karena balok A terlihat mengapung sehingga siswa berpikir bahwa gaya apung paling besar yaitu pada balok A. Padahal jika siswa fokus pada bagian awal soal tentang keadaan ketiga balok yang terapung dan memiliki penguasaan konsep yang cukup, siswa dapat memilih pilihan jawaban yang benar yaitu c. Hal ini menandakan bahwa penguasaan konsep siswa tentang gaya apung masih kurang. 


\section{PEMBAHASAN}

Temuan pada penelitian ini yaitu rata-rata perolehan skor penguasaan konsep siswa sebesar 33,06 dari rentang 0 - 100 . Hal ini menunjukkan bahwa penguasaan konsep siswa pada materi fluida statis maih sangat rendah. Terdapat beberapa kesulitan siswa yang ditemukan setelah siswa mengerjakan tes penguasaan konsep materi fluida statis ini. Siswa mengalami kesulitan saat menjawab soal yang berkaitan dengan Hukum Archimedes yang terdapat pada butir soal nomor 8 dan 9. Siswa belum sepenuhnya memahami tentang volume zat cair yang dipindahkan oleh benda dan siswa juga belum sepenuhnya menguasai tentang konsep gaya apung. Kesulitan siswa ini sebelumnya sudah pernah ditemui pada penelitian yang dilakukan oleh Wagner, dkk (2014) yang menemukan bahwa siswa masih mengalami miskonsepsi pada Hukum Archimedes. Selain itu, Yolanda (2017) juga menemukan bahwa siswa berpendapat bahwa faktor penyebab benda tenggelam atau terapung hanya terletak pada massa/berat benda.

Pada sub materi tekanan hidrostatis siswa mengalami kesulitan saat menjawab pertanyaan mengenai tekanan hidrostatis pada bejana berhubungan. Hal ini menandakan bahwa penguasaan konsep siswa mengenai Hukum Utama Hidrostatika perlu diasah lagi. Temuan penelitian ini sama seperti temuan pada penelitian yang sudah dilakukan Wijaya, dkk (2016) yang menemukan bahwa siswa masih menganggap tekanan hidrostatis bergantung pada bentuk ruang, bukan bergantung pada kedalaman atau ketinggian, gravitasi, dan massa jenis zat cair seperti yang dikatakan oleh Sahin, dkk (2010). Selain itu, Pratiwi dan Wasis (2013) juga menemukan bahwa siswa masih mengalami kesulitan dalam memahami konsep Tekanan Hidrostatis. Intinya pada temuan penelitian ini masih ditemukan beberapa kesulitan siswa dalam memahami fluida statis. Temuan ini sejalan dengan penelitian yang dilakukan Zuhri, dkk (2014) yang menemukan bahwa siswa mengalami miskonsepsi pada materi fluida statis.

Kelebihan dari penelitian ini dibandingkan dengan penelitian sebelumnya, penelitian ini menggunakan tes instrumen pilihan ganda dengan alasan yang memungkinkan untuk mengetahui penguasaan konsep siswa lebih mendalam tanpa membutuhkan banyak waktu untuk mengoreksi jika dibandingkan dengan soal yang berbentuk esai. Untuk kekurangan penelitian ini yaitu masih menggunakan sampel yang sedikit hanya 40 siswa. Selain itu, ada tambahan data mengenai penguasaan konsep fluida statis siswa dapat menggunakan metode selain metode survei, seperti melakukan wawancara semi terstruktur.

Untuk meningkatkan penguasaan konsep fluida statis siswa, terdapat beberapa saran pembelajaran berdasarkan penelitian yang telah dilakukan sebelumnya. Olympiou, dkk (2011) menemukan bahwa blended learning dapat digunakan untuk meningkatkan penguasaan konsep siswa. Selain itu, Interactive Demonstration Learning juga dapat digunakan untuk meningkatkan penguasaan konsep siswa (Mazzolini dkk, 2012; Tanahoung dkk, 2009; Sharma dkk, 2010). Crouch, dkk (2004) menemukan dengan memprediksi hasil demonstrasi sebelum siswa melihatnya, dapat menumbuhkan pemahaman yang lebih baik.

\section{SIMPULAN}

Berdasarkan analisis data dan pembahasan, maka dapat disimpulkan bahwa penguasaan konsep siswa kelas XII IPA 1 MAN 1 Pamekasan masih rendah. Meskipun sudah pernah mempelajari materi fluida statis pda saat kelas XI, rata-rata perolehan skor penguasaan konsep fluida statis siswa sebesar 33,06 dari rentang 0-100. Kesulitan siswa paling terlihat pada sub pokok bahasan Hukum Archimedes. Siswa belum menguasai konsep gaya apung dengan benar dan siswa masih perlu belajar lagi mengenai volume zat yang dipindahkan oleh benda.

Temuan pada penelitian ini memberikan gambaran kepada guru mengenai penguasaan konsep fluida statis siswa. Perlu adanya penelitian lebih lanjut guna menemukan pembelajaran yang sesuai dengan karakteristik belajar siswa, karena kesulitan siswa menguasai konsep fluida statis bisa dari berbagai macam faktor. Pembelajaran yang melibatkan keaktifan siswa dapat digunakan sebagai alternatif untuk meningkatkan penguasaan konsep siswa. Selain itu, pembelajaran yang di dalamnya siswa dapat membandingkan langsung antara konsep dan kenyataan yang siswa temui di lingkungan sekitar, seperti Interactive Demonstration Learning juga dapat digunakan sebagai alternatif pembelajaran.

\section{DAFTAR RUJUKAN}

Chang, C. Y., Kuang, Y. T., \& Barufaldi, J. P. (2010). The Positive and Negative Effects of Science Concept Tests on Student Conceptual Understanding. International Journal of Science Education, 32(2), 265-282.

Crouch, C., Fagen, A. P., Callan, J. P., \& Mazur, E. (2004). Classroom demonstrations: Learning Tools or Entertainment? American Journal of Physics, 72(6), 835-838. https://doi.org/10.1119/1.1707018

Docktor, J. L., \& Mestre, J. P. (2014). Synthesis of Discipline-Based Education Research in Physics. Physics Education Research, 10.

Fakcharoenphol, W., Morphew, J. W., Mestre, J. P. (2015). Judgments of Physics Problem Difficulty Among Experts and Novices. Physical Review Special Topics-Physics Education Research, 11 (2).

Goszewski, M., Moyer, A., Bazan, Z., \& Wagner, D. J. (2013). Exploring Student Difficulties with Pressure in a Fluid. AIP Conference Proceedings 1513, 154. 
Ipek, H, Kala, N, Yaman, E. \& Ayas, A. (2010). Using POE Strategy to Investigate Student Problem Solving in High School Physics. Physical Review Special Topics Physics Educatio Research. 11, 020-106.

Loverude, M. E., Heron, P. R. L., \& Kautz, C. H. (2010). Identifying and Addressing Student Difficulties with Hydrostatic Pressure. American Journal of Physics, 78(1), 75-85.

Loverude, Michael E., Kautz, C. H., \& Heron, P. R. L. (2003). Helping students develop an understanding of Archimedes' principle. I. Research on student understanding. American Journal of Physics, 71(11), 1178-1187.

Mazzolini, A. P., Daniel, S., \& Edwards, T. (2012). Using Interactive Lecture Demonstrations to Improve Conceptual Understanding of Resonance in an Electronics Course. Australasian Journal of Engineering Education, 18(1), $69-88$.

Miller, K, Lasry, N, Chu, N., \& Mazur, E. (2013). Role of Physics Lecture Demonstration in Conceptual Learning, Physical Review Special Topics - Physics Education Research. 9, 020-113.

Olympiou, Georgios., \& Zacharia, Zacharias C. (2011). Blending Physical and Virtual Manipulatives: An Effort to Students' Conceptual Understanding Through Science Laboratory Experimentation. Wiley Online Library. DOI $10.1002 /$ sce. 20463.

Ozcan, O. \& Gercek C. (2015). What are the Pre-Service Physics Teachers' Opinions about Context Based Approach in Physich Lessons?. Procedia Social and Behavioral Science 197, 889-897.

Pratiwi, A., \& Wasis. (2013). Pembelajaran dengan Praktikum Sederhana untuk Mereduksi Miskonsepsi Siswa pada Materi Fluida Statis di Kelas XI SMA Negeri 2 Tuban. Jurnal Inovasi Pendidikan Fisika, 2(3), 117-120.

Sahin, C, Ipek, H., \& Cepni, S. (2010). Computer Supported Conceptual Change Text: Fluid Pressure. Procedia Social and Behavioral Science. 2, 922-927.

Sharma, D. M., Johnston D. I., Johnston H., Varvell, K., Robertson, G., Hopkins, A., Stewart, C., Cooper, I. \& Thornton, R. (2010). Use of Interactive Lecture Demonstration: A Ten Year Study. Physical Review Special Topics-Physics Education Research, 6 (020119), 1-9.

Tanahoung, C., Chitaree, R., Soankwan, C., Sharma, Manjula D., Jhonston, Ian D. (2009). The effect of Interactive Lecture Demonstrations on Students' Understanding of Heat and Temperature: A Study from Thailand: Research in Science \& Technological Education, 1(27), 61-74.

Ünal, S., \& Coştu, B. (2005). Problematic issue for students: Does it sink or float? In Asia-Pacific Forum on Science Learning and Teaching (Vol. 6, pp. 1-16). The Education University of Hong Kong, Department of Science and Environmental Studies.

Wagner, D. J., Carbone, E., \& Lindow, A. (2014). Exploring Student Difficulties with Buoyancy (pp. 357-360). American Association of Physics Teachers.

Wijaya, P. C. Koes, S \& Muhardjito, H. (2016). The Diagnosis of Senior High School Class X Mia B Students Misconceptions about Hydrostatic Pressure Concept Using Three-Tier. Jurnal Pendidikan IPA Indonesia, 5(1), 14-21.

Wong, D., Lim, C., Munirah, S., \& Foong, S. K. (2010). Student and Teacher Understanding of Buoyancy. In Physics Education Research Conference.

Yin, Y., Tomita, M. K., \& Shavelson, R. J. (2008). Diagnosing and Dealing with Student Misconceptions: Floating and Sinking. Science Scope, 31(8), 34-39.

Yolanda, V. (2017). Analisis Miskonsepsi Siswa Dalam Pembelajaran Fisika Materi Fluida Statis Menggunakan Metode Certain of Response Index (Cri) Di Sman 7 Pekanbaru. Jurnal Online Mahasiswa (JOM) Bidang Keguruan dan Ilmu Pendidikan, 4(2), 1-9.

Zuhri, M. S., \& Jatmiko, B. (2014). Penerapan Model Pembelajaran Inkuiri (Inquiry Learning) menggunakan Phet Simulation untuk Menurunkan Miskonsepsi Siswa Kelas XI pada Materi Fluida Statis di SMAN Kesamben Jombang. Jurnal Inovasi Pendidikan Fisika, 3(3), 103-107. 